\title{
Raciocínio moral e uso abusivo de bebidas alcoólicas por adolescentes
}

\author{
Rita Melissa Lepre ${ }^{1}$ \\ Universidade Estadual Paulista Júlio de Mesquita Filho, Bauru-SP, Brasil \\ Raul Aragão Martins \\ Universidade Estadual Paulista Júlio de Mesquita Filho, São José do Rio Preto-SP, Brasil
}

\begin{abstract}
Resumo: O uso abusivo de álcool por adolescentes é uma questão que preocupa os envolvidos com a educação, uma vez que as consequências desse fato podem gerar sérios prejuízos ao processo ensino-aprendizagem e ao adolescente que abusa. Com o objetivo de contribuir para o debate na busca de uma intervenção efetiva que possa ser utilizada, sobretudo nas escolas, procuramos detectar a possível relação entre uso abusivo de álcool e raciocínio moral. Para tanto, participaram alunos do ensino médio de uma escola pública, selecionados por meio da aplicação do AUDIT (The Alcohol Use Disorder Identification Test), que posteriormente foram entrevistados, conforme a Moral Judgement Interview (MJ) proposta por Kohlberg. Os resultados obtidos revelam níveis e estágios morais aquém dos esperados. Concluímos que a prevenção pode ser pensada por meio da Educação Moral como uma proposta de intervenção efetiva contra o uso abusivo de álcool e outras drogas.
\end{abstract}

Palavras-chave: adolescência, abuso de álcool, desenvolvimento moral.

\section{Adolescents' moral reasoning and abusive alcohol use}

\begin{abstract}
Adolescents' abusive alcohol use is an issue that concerns professionals involved with education because its consequences can lead to serious damages to the learning-teaching process and to adolescents who present abusive consumption. Aiming to contribute to the discussion on the search for an effective intervention, especially at schools, we attempted to find the possible relation between the abusive use of alcohol and moral reasoning. For that, secondary students from a public school were selected through the AUDIT (The Alcohol Use Disorder Identification Test) and then were interviewed using the Moral Judgment Interview (MJI) proposed by Kohlberg and colleagues. Results reveal moral levels and stages bellow the expected. We conclude that prevention can be considered in the perspective of Moral Education as an effective proposal against the abusive use of alcohol and other drugs.
\end{abstract}

Keywords: adolescence, alcohol abuse, moral development.

\section{Razonamiento moral y uso abusivo del alcohol por adolescentes}

\begin{abstract}
Resumen: El abuso de la ingesta de alcohol por parte de los adolescentes es un tema que preocupa a los que trabajan en educación, porque las consecuencias de este hecho pueden generar serios deterioros al proceso de enseñaza-aprendizaje y al adolescente involucrado en este tipo de conductas. Con el objetivo de contribuir en el debate de la búsqueda de una intervención efectiva que pueda ser utilizada sobretodo en las escuelas, buscamos detectar la posible relación entre el uso abusivo del alcohol y el razonamiento moral. Para esto, participaran alumnos de la enseñanza media de una escuela pública. Seleccionamos a los participantes por medio de la aplicación de AUDIT (The Alcohol Use Disorder Identification Test) y, posteriormente, los entrevistamos utilizando la Moral Judgement Interview (MJ), propuesta por Kohlberg y colaboradores. Los resultados obtenidos revelan niveles y estadios morales por debajo de lo esperado. Concluimos que la prevención pueda ser pensada por medio de la Educación Moral como una propuesta de intervención efectiva contra el consumo abusivo de alcohol y otras drogas.
\end{abstract}

Palabras clave: adolescencia, abuso de alcohol, desarrollo moral.

O consumo de drogas ilícitas por adolescentes, como a maconha e a cocaína, é relativamente baixo quando comparado ao uso das drogas lícitas, como o álcool e o tabaco (Galduróz, Noto, \& Carlini, 1997). Ao contrário das drogas ilícitas, o primeiro contato que a maioria dos adolescentes tem com o álcool ocorre dentro de casa, sob o olhar complacente da família, que aceita e tolera esse tipo de substância. Essa postura familiar sinaliza a idéia de que o álcool, quando devidamente utilizado em situações sociais, tem boas funções, como promover encontros sociais ou o "relaxamento" após um dia estafante. O problema é que esse uso nem sempre é devido e o exemplo exibido não é o da taça de champanha

1 Endereço para correspondência:

Prof. ${ }^{\text {a }}$ Dr. ${ }^{\text {a }}$ Rita Melissa Lepre. Universidade Estadual Paulista. Faculdade de Ciências de Bauru. Departamento de Educação. Av. Eng. Luiz Edmundo Carrijo Coube, 14-01. CEP 17033-360. Bauru-SP, Brasil. E-mail:melissa@fc.unesp.br para brindar o ano novo, ou o de um copo de chope, no final de semana, mas de doses diárias para "esquecer dos problemas" ou ficar "um pouco mais alegre".

A idéia de fazer do álcool um aliado do prazer lícito não é atual, data da Antigüidade, mais especificamente visível no Império Romano. Havia, nessa época, uma tendência aos prazeres e excessos, como por exemplo, o uso abundante do vinho (ideologia báquica), representado pela figura do deus Baco da mitologia grega, deus do prazer e da sociabilidade. Numa sociedade em que o prazer não era menos legítimo do que a virtude, representada por Hércules, o vinho ocupava um lugar privilegiado, ainda que já se soubesse de seus efeitos negativos (Áries \& Duby, 1990).

Atualmente, o álcool, cientificamente conhecido como etanol (álcool etílico), é a droga mais consumida em todo o mundo. O estudo realizado por Galduróz, Noto e Carlini (1997), por intermédio do Centro Brasileiro de Informações 
sobre Drogas Psicotrópicas (CEBRID), com estudantes de escolas de ensino fundamental e médio de dez capitais brasileiras, revelou que o álcool e os solventes são as drogas mais consumidas por adolescentes. O álcool, considerando-se o uso pelo menos uma vez na vida, é a droga mais consumida em todas as faixas etárias, começando entre os dez e os doze anos. A pesquisa revela, ainda, que $65 \%$ dos alunos pesquisados já consumiram essa droga pelo menos uma vez na vida. A cerveja foi a bebida mais apontada pelos adolescentes, sendo que $70 \%$ destes relataram seu uso, seguido pelo vinho (27\%) e pelos destilados $(3 \%)$.

Esse consumo aumentou drasticamente com a produção de bebidas alcoólicas em escala industrial e, particularmente, após sua inserção na sociedade de consumo como mais uma mercadoria a ser vendida à população. A associação entre a produção em massa e a divulgação, via campanhas publicitárias, fez com que a produção brasileira de cerveja, a bebida alcoólica mais consumida entre os jovens, alcançasse a expressiva marca de 9 bilhões de litros anuais, no ano de 2005 (Siqueira, 2005).

Além da exposição a propagandas muito bem elaboradas, os jovens e a sociedade de uma forma geral, não associam bebidas alcoólicas a drogas (Vivarta, 2003; Gomide \& Pinsky, 2004). Esses fatos têm feito com que o uso abusivo de álcool venha aumentando, consideravelmente, entre os adolescentes brasileiros (Galduróz, Noto, Fonseca, \& Carlini, 2005; Pinsky \& Bessa, 2004).

O uso abusivo de álcool é caracterizado pelo forte vínculo com essa substância, que interfere nas relações intra e interpessoais de quem abusa. Em relação ao álcool, o abuso é caracterizado como o uso contínuo de bebidas alcoólicas, apesar dos problemas causados ou intensificados por seu consumo. "O abuso de álcool é essencialmente um padrão de ingestão que resultou em efeitos deletérios à saúde, dificuldades sociais e/ou problemas legais" (Dimeff, Baer, Kivlahan, \& Marlatt, 2002, p. 19).

Os riscos e as consequências do uso abusivo de álcool na escola levam à queda acentuada no desempenho escolar. Adolescentes que bebem demais se ausentam com maior frequência das aulas, perdendo a totalidade do processo pedagógico. Aqueles que conseguem frequentar as aulas apresentam sonolência, lentidão e dificuldade para entender o que o professor diz. Algumas pesquisas apontam para danos cerebrais (no hipocampo) causados pelo uso abusivo de álcool, envolvendo o aprendizado e a memória. Segundo Herculano-Houzel (2002), o hipocampo é o local do cérebro no qual a memória é formada e depois distribuída para o resto dele. Danos no hipocampo poderiam prejudicar a formação de novas memórias, o que atrapalharia muito as novas aprendizagens.

Acredita-se que a entrada (e a permanência) no mundo das drogas, lícitas ou ilícitas, não é uma questão que se dá ao acaso. Pensa-se, igualmente, que seja produzida de alguma maneira, diariamente, talvez pela ordem social vigente e hegemônica (que adota uma visão simplista do adolescente como consumidor), pelos modelos sociais da sociedade capitalista, pela construção da moralidade prejudicada por essa sociedade consumista e individualista ou uma mistura desses fatores. Nesta perspectiva, buscou-se relacionar o uso abusivo de álcool por adolescentes com o desenvolvimento do raciocínio moral, tendo como referencial teórico as pesquisas de Lawrence Kohlberg (1992) e os estudos de autores espanhóis sobre a Educação Moral e em valores (Puig, 1998a, 1998b; Díaz-Aguado \& Medrano, 1999; Buxarrais, 2000).

A pesquisa que apresentamos neste artigo traz as seguintes indagações: qual o nível e estágio de desenvolvimento do raciocínio moral de adolescentes que fazem uso abusivo de álcool? Qual a melhor maneira de se trabalhar a prevenção ao uso abusivo de álcool com esses adolescentes?

\section{Revisão de literatura}

A teoria do raciocínio moral de Kohlberg (1992) teve como base a proposta sobre o desenvolvimento moral de crianças de Piaget (1994), mas evoluiu para explicar o raciocínio moral de adolescentes e adultos norte-americanos, pelo fato de, nas primeiras pesquisas, chegar à conclusão de que os conceitos de heteronomia e autonomia, propostos por Piaget, eram insuficientes para classificar e categorizar todos os tipos de raciocínio moral que tinham aparecido entre os adolescentes estudados. Para compreender melhor os dados encontrados, Kohlberg (1992) propõe três níveis de desenvolvimento, que, por sua vez decompõem-se em seis estágios. Um primeiro nível, o pré-convencional, no qual estão os estágios 1 e 2. Nesse nível, as crianças - até por volta dos nove anos de idade - decidem o que é certo fazer baseadas somente em interesses próprios ou no medo da punição. As questões morais são colocadas considerando-se apenas o interesse das pessoas implicadas, com ênfase nas próprias necessidades.

O segundo nível é o convencional, no qual estão os estágios 3 e 4 . Nesse nível, a ação certa é aquela pautada nas convenções sociais determinadas por pessoas que se apresentem enquanto autoridades ou instituições reconhecidas socialmente. $\mathrm{O}$ indivíduo emite juízos tendo como referência as regras do grupo e as expectativas que este tem sobre ele. Os temas morais se apresentam como meio para haver adequação social.

O terceiro e último nível é o pós-convencional, no qual estão os estágios 5 e 6 (menos encontrados por Kohlberg). Nesse nível, a ação certa é aquela guiada por princípios morais universais, pautados na reciprocidade e na igualdade. $\mathrm{O}$ pensamento é regido por princípios e não por regras sociais, que só serão aceitas se estiverem fundamentadas em princípios e valores gerais.

Kohlberg (1992) lembra que o raciocínio moral é claramente um raciocínio e, assim sendo, o raciocínio moral avançado se baseia em um raciocínio lógico avançado. Existe um paralelismo entre o estágio lógico de um indivíduo e seu estágio moral. Assim, apenas pessoas do estágio operatório- 
formal estariam possibilitadas para construir um raciocínio moral autônomo, do nível pós-convencional (estágios 5 e 6). No entanto, se o desenvolvimento lógico é uma condição necessária ao desenvolvimento moral, não é uma condição suficiente. Vários indivíduos apresentam um estágio lógico mais alto que seu estágio moral, mas nunca um estágio moral mais alto que seu estágio lógico.

Segundo Kohlberg (1992), seus estudos encontram-se no grupo das teorias cognitivo-evolutivas, tendo como base os seguintes pressupostos:

(1) o desenvolvimento inclui transformações básicas das estruturas cognitivas, que não podem ser explicadas por meio dos parâmetros da aprendizagem associacionista (reforço, repetição, dentre outros), mas por parâmetros de totalidades organizativas ou sistemas de relações internas;

(2) o desenvolvimento das estruturas cognitivas resulta de processos de interação entre o organismo e o meio em que a pessoa está inserida;

(3) as estruturas cognitivas são sempre estruturas de ação sobre objetos que evoluem de esquemas sensório motores para esquemas simbólicos;

(4) o desenvolvimento das estruturas cognitivas leva a formas superiores de equilíbrio, o que otimiza a interação e a reciprocidade entre a ação do organismo sobre o objeto - ou situações - e a ação do objeto sobre o organismo.

Pactuando com esses pressupostos, um grupo de pesquisadores espanhóis lotados no Grupo de Ricierca en Educación Moral (GREM) vem desenvolvendo estudos sobre a Educação Moral e os valores na escola (Puig, 1998a, 1998b; Díaz-Aguado \& Medrano,1999; Buxarrais, 2000). Puig (1998b) define a Educação Moral em valores como um âmbito de reflexão individual e coletiva que permita a elaboração racional e autônoma de princípios de valor que auxiliem o indivíduo a defrontar-se com questões da realidade, como a violência ou a guerra. "E, finalmente, a Educação Moral quer formar hábitos de convivência que reforcem valores como a justiça, a solidariedade, a cooperação ou o cuidado com os demais" (Puig, 1998b, p. 16).

O principal objetivo da Educação Moral é possibilitar ao educando o desenvolvimento de capacidades que intervêm no raciocínio e na ação moral, para que este possa orientar-se de forma racional e autônoma em determinadas situações em que lhe é apresentado um conflito de valor. Podemos pensar, por exemplo, que um adolescente pode enfrentar um conflito de valor quando é pressionado pelo grupo de amigos a ingerir bebidas alcoólicas, nesse caso, ajudá-lo a fazer uma escolha racional seria meta da Educação Moral.

Buxarrais (1997) define três modelos de Educação Moral que diferem entre si quanto aos objetivos, métodos e filosofia de trabalho: os modelos baseados em valores absolutos, os modelos baseados em valores relativos e os modelos baseados na construção racional e autônoma de valores.

Os modelos de Educação Moral baseados em valores absolutos apresentam uma visão de mundo pautada em valores e normas de conduta indiscutíveis e imutáveis, que são impostos por um poder autoritário, passados como dogmas e não passíveis de serem discutidos. Pretendem regular todos aspectos da vida social e pessoal dos indivíduos, por meio da coação ou de políticas sociais dogmáticas. Não pretendem formar indivíduos pensantes que possam optar, discutir, dialogar, mas sim fabricar representantes dos valores elegidos como os melhores. Tais modelos têm como referência uma visão de cidadão pré-concebida e a Educação Moral deve ser a responsável por essa reprodução. Um exemplo desse modelo foi a Educação Moral e Cívica, oferecida nas escolas brasileiras, durante a ditadura militar, na qual se buscava doutrinar os alunos, inculcando-lhes a ideologia dominante.

Opostamente, os modelos de Educação Moral baseados em valores relativos defendem que os valores e as normas de conduta são critérios totalmente subjetivos. Dessa forma, não deve haver consenso sobre a melhor forma de agir em determinada situação, uma vez que tal resolução depende das características pessoais de cada um. As decisões devem ser sempre individuais e nunca coletivas, do contrário, feririam o princípio da pessoalidade. O papel da Educação Moral, nesse caso, é quase nulo, pois não há o que se ensinar já que os julgamentos morais dependem exclusivamente da subjetividade de cada um. Esse modelo de Educação Moral tem como base uma ética pessoal que paradoxalmente se anula, uma vez que essa deve estar pautada em princípios universais.

Por fim, existem os modelos de Educação Moral baseados na construção racional e autônoma de valores. É nesta terceira concepção que se encontram os trabalhos de Kohlberg (1992), Puig (1998a,1998b), Díaz-Aguado \& Medrano (1999), Buxarrais $(1997,2000)$, dentre outros. Nesses modelos procuram-se propor situações que facilitem a construção da autonomia por parte do educando. Segundo Buxarrais (1997), trata-se de trabalhar a dimensão moral da pessoa para desenvolver sua autonomia, racionalidade e o uso do diálogo como forma de construir princípios e normas que afetem o modo de pensar e agir e que orientem o sujeito em situações de conflitos de valores. Este estudo foi desenvolvido tendo essa concepção de Educação Moral como referência.

\section{Método}

Com o propósito de responder às questões levantadas, realizamos um estudo sobre o raciocínio moral de adolescentes, entre 14 e 18 anos, que fazem uso abusivo de álcool, estudantes de uma escola pública de ensino médio em AssisSP, tendo como principal base teórica os estudos de Kohlberg (1992) sobre a moralidade humana, além das novas contribuições trazidas por autores espanhóis no campo da Educação Moral e em valores, tais como Puig (1998a, 1998b), Díaz-Aguado e Medrano (1999) e Buxarrais (2000).

Para alcançar os objetivos deste estudo, a pesquisa foi realizada em duas etapas. A primeira, de caráter quantitativo, compreendeu a identificação de alunos de ensino médio que apresentavam o comportamento de beber abusivamente. 
A segunda parte, de caráter qualitativo, investigou o raciocínio moral dos alunos identificados na primeira.

\section{Local da pesquisa}

O estudo foi realizado em uma escola estadual de AssisSP, no período de 2004 a 2005, que oferece o ensino médio como modalidade de ensino. Trata-se de uma escola situada em um bairro de classe média que recebe alunos de diversos outros bairros da cidade, provenientes de níveis sócioeconômicos menos privilegiados. Segundo informações da coordenadora pedagógica, obtidas por meio de entrevista, a escola enfrenta problemas com alunos que fazem uso de álcool, inclusive no recinto da própria escola.

\section{Participantes}

Participaram do estudo alunos do $1^{\circ}, 2^{\circ}$ e $3^{\circ}$ anos do ensino médio. Na primeira etapa, responderam ao instrumento de levantamento inicial 171 alunos, com média de idade de 16 anos, não apresentando diferença significativa entre os sexos. Este número representa a totalidade dos alunos de ensino médio do período da manhã. A segunda fase foi composta, inicialmente, por 34 alunos, selecionada por apresentarem padrão de beber de risco. Esse grupo representa 19,9\% da amostra inicial, somente 27 deles estavam frequentando a escola na ocasião da realização da segunda etapa, sendo posteriormente entrevistados.

\section{Instrumentos}

Na primeira etapa, o instrumento utilizado foi o AUDIT (The Alcohol Use Disorder Identification Test), no intuito de identificar os adolescentes com padrão de beber de risco. O AUDIT foi criado em meados da década de 1980 (Babor, Biddle-Higgins, Saunders, \& Monteiro, 2001) com o objetivo de identificar usuários de risco, medindo consumo, sintomas de dependência e consequências pessoais e sociais do beber excessivo. O questionário é composto por dez questões: três relacionadas ao uso de álcool, quatro sobre dependência e três sobre problemas decorrentes do consumo, tendo como foco os últimos doze meses. Os escores vão de 0 a 40, sendo que uma pontuação igual ou superior a 8 indica uso nocivo de álcool.

Para a segunda etapa, de caráter qualitativo, utilizou-se a forma A da entrevista semi-estruturada de Kohlberg (Moral Judgment Interview-MJI), no intuito de verificar o nível e o estágio do raciocínio moral dos adolescentes participantes. Esta forma é composta de três dilemas, nos quais o participante tem que fazer uma escolha, que envolve um conflito moral, e justificá-la. No primeiro dilema, a escolha é entre roubar ou não e o conflito é entre preservar a vida ou obedecer a lei. O segundo é sobre punir alguém ou não e o conflito se dá entre aplicação da lei (punição) e a consciência pessoal e, por fim, o último dilema é sobre recusar ou não um pedido paterno e o conflito é sobre obediência a um contrato préestabelecido ou submissão à autoridade.

\section{Procedimentos}

Na coleta de dados, procedemos da seguinte forma: (a) entramos em contato com a direção de uma escola pública do Estado de São Paulo, a fim de obter autorização para a realização da pesquisa; (b) obtida a autorização, entramos em contato com os alunos do ensino médio, informando-os sobre a pesquisa e pedindo autorização aos pais para a realização do estudo com seus filhos (assinatura do Termo de Consentimento Livre e Esclarecido, segundo a Resolução 196/96 do Conselho Nacional de Saúde); (c) realizamos o levantamento inicial nas turmas de ensino médio da escola e, no decorrer dos contatos (pedido de autorização e aplicação do levantamento inicial), procuramos estabelecer vínculo com os participantes, que foi reforçado por meio de visitas à escola e conversas informais no pátio, na entrada e na saída das aulas; (d) em posse dos resultados do AUDIT, passamos para as entrevistas individuais, tendo o cuidado de incluir, na amostra, cinco alunos que tiveram pontuação 0 no AUDIT, evitando a identificação dos participantes.

\section{Análise de dados}

Na primeira parte do estudo, foram avaliados os resultados do AUDIT. Na segunda, foram analisados os dados obtidos por meio das entrevistas realizadas com os adolescentes. Tendo como referência o Standard Issue Scoring Manual (The measurement of moral judgment) de Colby e Kohlberg (1987), buscamos realizar uma avaliação qualitativa do raciocínio moral dos participantes atendo-nos aos pressupostos metodológicos da teoria em questão.

Segundo Biaggio (2002), a formulação mais recente da teoria de Kohlberg considera a avaliação da entrevista de julgamento moral como uma atividade interpretativa hermenêutica. Buscamos, pois, analisar qualitativamente as entrevistas realizadas, tendo como critérios as características dos níveis e estágios propostos por Kolhberg (1992), segundo o método hermenêutico e as formulações mais recentes da teoria kohlberguiana.

\section{Aspectos éticos}

Após a direção da escola autorizar a realização da pesquisa, entramos em contato com os alunos, informando-os sobre a pesquisa e pedindo autorização aos pais para a realização do estudo com seus filhos. Desta feita, os responsáveis assinaram o Termo de Consentimento Livre e Esclarecido, segundo a Resolução 196/96 do Conselho Nacional de Saúde.

$\mathrm{Na}$ realização desse estudo, adotamos procedimentos para evitar a identificação dos participantes selecionados como usuários abusivos de álcool, entrevistando, também, alguns alunos que não apresentaram nenhum indício de abuso no AUDIT. Dessa forma, não era possível aos demais alunos da classe identificar se o colega entrevistado faz ou não uso abusivo de álcool, uma vez que pessoas que não bebem também foram entrevistadas. Entrevistamos, no total, cinco alunos que apresentaram AUDIT com pontuação nula. 
As entrevistas foram abreviadas (apenas o dilema I). Como nosso estudo não teve objetivo comparativo, não analisamos as respostas dos participantes desse grupo, desconsiderando sua validade.

\section{Resultados}

A avaliação do raciocínio moral dos adolescentes participantes nos permitiu constatar que $56 \%$ encontram-se no Nível Pré-Convencional (13\% no estágio 1 e $87 \%$ no estágio 2) e $44 \%$ encontram-se no Nível Convencional (100\% no estágio 3).

Segundo Kohlberg (1992), para se entender melhor as características de cada nível é importante considerar a relação entre o eu, as normas e as expectativas da sociedade. As pessoas do nível Pré-Convencional acreditam que as normas e as expectativas sociais são algo externo a elas. As pessoas do nível Convencional se identificam com as normas e as expectativas sociais, sobretudo vindas de autoridades. As pessoas do nível Pós-Convencional diferenciam seu eu das normas e expectativas sociais, definindo seus valores segundo princípios auto-escolhidos. É possível constatar que, em certo sentido, os indivíduos do nível Pré-Convencional e Pós-Convencional apresentam um ponto de vista similar, uma vez que julgam o bem e o mal de fora da sociedade. No entanto, há uma grande diferença entre eles, pois enquanto os primeiros raciocinam em função de expectativas individuais e consequências externas, os últimos têm, como referência de seu raciocínio, a totalidade do gênero humano, ampliando sua perspectiva para além do grupo ou sociedade em que se situa o indivíduo do nível convencional, chegando a reconhecer direitos universais (Díaz-Aguado \& Medrano, 1999).

Na pesquisa realizada, 56\% (15 entrevistados) dos participantes encontram-se no nível pré-convencional. O raciocínio moral desses adolescentes baseia-se nas consequências imediatas de seus atos, o que os leva a acreditar que o correto é aquilo que não lhes traga punições externas e que defenda seus interesses pessoais. Os outros 44\% (12 entrevistados) encontram-se no nível convencional, portanto, seu raciocínio moral baseia-se nas expectativas sociais, especialmente aquelas vindas de autoridades (governantes, pais, professores, igreja, dentre outras).

A definição dos estágios permite uma análise profunda acerca do raciocínio moral dos sujeitos. Considerando as características gerais dos níveis, os estágios apresentam os pormenores relativos ao raciocínio moral dos indivíduos. $\mathrm{O}$ estágio 1 (moralidade heterônoma) "se caracteriza por um ingênuo realismo moral que leva a compreender o significado moral de uma situação como uma qualidade física inerente à própria ação, de forma similar à cor ou ao tamanho que caracterizam um determinado objeto" (Díaz-Aguado \& Medrano, 1999, p. 67). Isso significa que o raciocínio moral justifica-se por meio das regras existentes que se aplicam de forma absoluta ou literal, não considerando as circunstâncias que estão envolvidas na situação. Um simples "é proibido" ou "é errado" pode justificar o juízo moral dos sujeitos do estágio 1. Essa característica de raciocínio moral é denominada realismo moral e absolutismo, podemos notá-la na resposta do participante C9 frente ao dilema III' (Moralidade/Consciência/Castigo):
Deve-se castigar uma pessoa que contraria a lei, agindo segundo sua consciência? Por quê?
Tem que castigar, porque independente do que a pes- soa pensa, está errado roubar. (Participante C 9)
E, por que é errado roubar?
Porque é errado! (Participante C 9)

A resposta do participante $\mathrm{C} 9$ pauta-se num argumento extremamente simples. O fato de "ser errado" é o bastante para fazê-lo acreditar que o protagonista do dilema deve ser punido pelo que fez. O estágio 2 (moralidade individualistainstrumental), mais encontrado entre os participantes dessa pesquisa, caracteriza-se "por una perspectiva individualista concreta. Hay una conciencia de que cada persona tiene sus propios intereses a perseguir y que estos intereses pueden entrar en conflicto" (Kohlberg, 1992, p. 575). O que é moralmente correto define-se em termos do prazer ou da satisfação das necessidades da pessoa (hedonismo). Nesse estágio, o sujeito acredita ser correto seguir as normas por interesses próprios e deseja que os outros façam o mesmo. O participante A1 demonstra essa característica na sua resposta ao dilema III, sobre a escolha de Henrique roubar ou não o remédio.

\section{Deveria Henrique roubar o remédio? Por quê? Não, ele não pode roubar o remédio. $O$ direito de vender é do farmacêutico. O remédio é dele. (Par- ticipante A1)}

Outra característica marcante é a reciprocidade simples e concreta que pode ser definida pelo "olho por olho, dente por dente". O participante A7 ilustra essa questão em sua resposta ao dilema $\mathrm{I}$.

\section{Deveria João negar-se a dar o dinheiro ao pai? Por quê? \\ Não, ele não deve negar. O pai se esforçou para criá-lo e agora é a sua vez de retribuir. (Participante A7)}

Os indivíduos do estágio 2 raciocinam de acordo com uma perspectiva social individualista e concreta, que os levam a interpretar de forma relativista o dever moral. Buscam garantir, ao máximo, a satisfação de suas necessidades e desejos, reduzindo, ao mínimo, as consequências negativas para si mesmo. Visando relacionar essas características do raciocínio moral ao comportamento de uso abusivo de drogas, sobretudo do álcool, podemos dizer que o ato de beber abusivamente é considerado satisfatório e inócuo desde que 
não gere consequências externas imediatas, como ser flagrado dirigindo embriagado pela polícia, bater o carro ou se machucar fisicamente.

O estágio 3 é considerado o estágio da moralidade da normativa interpessoal ou "do bom menino". Os sujeitos desse estágio estão preocupados com as relações interpessoais no sentido de manter a confiança e a aprovação social. "As obrigações morais se baseiam no que esperam os demais; adotando, nesse sentido, uma perspectiva convencional" (Díaz-Aguado \& Medrano, 1999, p. 79). O participante B2, com raciocínio moral no estágio 3 , oferece a seguinte resposta ao dilema III:

\section{Deveria Henrique roubar o remédio? Por quê? Sim, ele devia roubar o remédio porque quis salvar a vida da mulher dele. (Participante B2) \\ É bom ou mal que ele faça isso? \\ É bom, ele não deixou a mulher que ele ama morrer. Ele é o marido dela e não poderia deixar que ela morresse assim. (Participante B2)}

A possibilidade de estabelecer relações de confiança mútua transcende os interesses e situações particulares, adotando a perspectiva de uma terceira pessoa. O comportamento moralmente correto é aquele que leva à aprovação dos outros. No entanto, a visão deste estágio ainda é egocêntrica e a moralidade está ligada ao conformismo e a estereótipos do tipo "Um bom marido deve salvar a vida da mulher", como é o caso do exemplo oferecido acima. Como resultado de uma perspectiva socialmente compartilhada, o sujeito do estágio 3 está particularmente preocupado com sua aprovação social e confiança pessoal. Aquilo que considera certo é o que julga ser o esperado pelos outros. O participante $\mathrm{C} 5$ revela esse raciocínio quando é questionado se o juiz deveria assinar uma sentença a Henrique e por que, no dilema III':

O juiz deveria assinar uma sentença a Henrique ou deveria suspendê-la e deixá-lo livre?

Deveria assinar uma sentença. Apesar de salvar a vida da mulher, ele cometeu um crime. (Participante C5)

E por que isso é o melhor?

Porque as pessoas esperam que aqueles que fizeram alguma coisa errada paguem por isso. (Participante C5)

Henrique fez alguma coisa errada?

Fez. Ele salvou uma vida, mas roubou, e roubar não é o que ele deveria ter feito. (Participante C5)

As diversas pesquisas realizadas por Kohlberg (1992) revelam que o estágio 3 começa a se construir em torno dos 12 anos de idade e caracteriza o raciocínio da maioria dos adolescentes e adultos de diversas sociedades.

$\mathrm{Na}$ pesquisa apresentada, as entrevistas realizadas para avaliar o nível e o estágio de raciocínio moral dos adolescentes, que fazem uso abusivo de álcool, revelaram que, dos 27 adolescentes participantes, 56\% encontram-se no nível pré-convencional, sendo que $13 \%$ pertencem ao estágio 1 e $87 \%$ ao estágio 2 . Os $44 \%$ dos adolescentes restantes encontram-se no nível convencional, todos no estágio 3. Na população estudada, tais resultados indicam um desenvolvimento moral aquém do esperado para a idade e sugerem possível relação entre moralidade e uso abusivo de álcool.

\section{Considerações finais}

Os resultados da pesquisa revelam que a maioria (56\%) dos adolescentes que faz uso abusivo de álcool, na população estudada, apresentou raciocínio moral pré-convencional (estágio 1 e 2). Segundo Kohlberg (1992), o raciocínio pré-convencional é próprio de crianças ou adolescentes infratores, sendo que o mais comum de ser encontrado na adolescência é o nível convencional, ainda que já haja a possibilidade de se construir raciocínios morais mais autônomos, tendo-se como referência as estruturas cognitivas do período operatório-formal.

Ao encontrarmos os resultados descritos, pudemos verificar que esses adolescentes apresentam um raciocínio moral pouco desenvolvido e com estilo heterônomo, o que, a nosso ver, pode dificultar sua conduta moral e, consequentemente, facilitar seu envolvimento com o uso abusivo de drogas. Acreditamos que uma das formas possíveis de se trabalhar a prevenção possa ser por meio da Educação Moral. Propor a prevenção via Educação Moral nos possibilita pensar que o desenvolvimento da autonomia possa produzir um comportamento mais consciente em relação às drogas, assim como em relação às demais situações que envolvem escolhas ou decisões morais. Qualquer proposta de Educação Moral que busca o amadurecimento do julgamento moral baseia-se na idéia de que esse possa refletir no comportamento ou ação moral do indivíduo.

Ao propormos a Educação Moral como possibilidade preventiva ao abuso de drogas e, mais especificamente, ao uso abusivo de álcool, acreditamos que seja possível auxiliar $o$ adolescente a construir um julgamento moral mais elevado que lhe possibilitaria uma ação mais consciente em relação às drogas, por exemplo. Segundo Díaz-Aguado e Medrano (1999, p. 37), "a coerência entre o juízo e a conduta moral depende, entre outras variáveis, do nível de autonomia, pois aumenta consideravelmente à medida que o pensamento dos sujeitos se aproxima do nível pós-convencional".

Ter verificado que nossos participantes apresentam um raciocínio moral heterônomo fortalece nossa hipótese de que a prevenção, via Educação Moral, seria favorável para trabalhar a questão do envolvimento dos adolescentes com o uso abusivo de álcool e outras drogas. É importante esclarecermos que um programa de Educação Moral voltado para esse fim em nada difere de outras propostas. O que se espera é que, com o desenvolvimento da autonomia, o indivíduo possa ter uma ação moral mais comprometida consigo 
mesmo e com os outros e, consequentemente, evitar o uso abusivo de drogas, assim como evitar outros comportamentos que possam trazer consequências negativas para si e para terceiros. Acreditamos que o fato de se fazer uso abusivo de álcool - e drogas em geral - é uma questão ampla, multifatorial, e não estamos querendo reduzi-la à dimensão moral. Igualmente, pensamos que o presente estudo revela uma face importante relacionada ao uso abusivo de drogas até então pouco investigada: a dimensão moral.

\section{Referências}

Áries, P., \& Duby, G. (1990). História da vida privada I. Porto, Portugal: Afrontamento.

Babor, T. F., Biddle-Higgins, J. C., Saunders, J. B., \& Monteiro, M. G. (2001). AUDIT: The alcohol use disorders identification test: Guidelines for use in primary care. Geneva: WHO.

Biaggio, A. M. B. (2002). Lawrence Kohlberg: Ética e educação moral. São Paulo: Moderna.

Buxarrais, M. R. (1997). La formación del profesorado en educación en valores: Propuesta y materiais. Bilbao: Desclée de Brouwer.

Buxarrais, M. R. (2000). La formación del profesorado en educación en valores. Bilbao: Desclée.

Colby, A., \& Kohlberg, L. (1987). The measurement of moral judgement. Nova York: Cambridge University Press.

Díaz-Aguado, M. J., \& Medrano, C. (1999). Construção moral e educação: Uma aproximação construtivista para trabalhar os conteúdos transversais. Bauru, SP: EdUSC.

Dimeff, L. A., Baer, J. S., Kivlahan, D. R., \& Marlatt, G. A. (2002). Alcoolismo entre estudantes universitários: Uma abordagem de redução de danos. São Paulo: EdUnesp.

Galduróz, J. C. F., Noto, A. R., \& Carlini, E. A. (1997). IV Levantamento sobre uso de drogas entre estudantes de $1^{\circ}$ e $2^{\circ}$ graus em 10 capitais brasileiras. São Paulo: CEBRID/Universidade Federal de São Paulo-Escola Paulista de Medicina.

Galduróz, J. C. F., Noto, A. R., Fonseca, A. M., \& Carlini, E. A. (2005). V Levantamento sobre o uso de drogas psicotrópicas entre estudantes do ensino fundamental e médio da rede pública de ensino nas 27 capitais brasileiras, 2004. São Paulo: CEBRID/Universidade Federal de São Paulo-Escola Paulista de Medicina.

Gomide, P. I. C., \& Pinsky, I. (2004). A influência da mídia e o uso das drogas na adolescência. In I. Pinsky \& M. A. Bessa (Orgs.), Adolescência e drogas. São Paulo: Contexto.

Herculano-Houzel, S. (2002). O cérebro nosso de cada dia: Descobertas da neurociência sobre a vida cotidiana (2a ed.). Rio de Janeiro: Vieira \& Lent.

Kohlberg, L. (1992). Psicologia del desarrolo moral. Bilbao: Edit Desclée de Brouwer.
Pinsky, I., \& Bessa, M. A. (2004). Adolescência e drogas. São Paulo: Contexto.

Piaget, J. (1994). O juízo moral na criança. São Paulo: Summus.

Puig, J. M. (1998a). A construção da personalidade moral. São Paulo: Ática.

Puig, J. M. (1998b). Ética e valores: Métodos para um ensino transversal. São Paulo: Casa do Psicólogo.

Siqueira, A. (2005, Outubro). Pronta para brindar: Consumo depois de uma década de baixo crescimento, a indústria está prestes a chegar à produção de 9 bilhões de litros de cerveja. Carta Capital, 12(363), 50-51.

Vivarta, V. (2003). Equilíbrio distante: Tabaco, álcool e a adolescência no jornalismo brasileiro. São Paulo: Cortez.

Rita Melissa Lepre é Professora Assistente Doutora do Departamento de Educação da Faculdade de Ciências da Universidade Estadual Paulista Júlio de Mesquita Filho, campus Bauru.

Raul Aragão Martins é Professor Adjunto de Psicologia do Departamento de Educação do Instituto de Biociências, Letras e Ciências Exatas da Universidade Estadual Paulista Júlio de Mesquita Filho, campus Bauru.

Recebido: $15 / 05 / 2008$

$1^{a}$ revisão: 02/03/2009

Aceite final: 03/04/2009 